\title{
MODELO DE GESTÃO POR COMPETÊNCIAS: A ADERÊNCIA DOS GESTORES PARA O ALCANCE DO DESEMPENHO ORGANIZACIONAL SUPERIOR
}

\author{
COMPETENCIES MANAGEMENT MODEL: AN ADHERENCE BY \\ ORGANIZATION HEADS TO ACHIEVE A SUPERIOR PERFORMANCE
}

Giselle Inês Borges Avelino Pontifícia Universidade Católica de Minas Gerais giselleiborges@ hotmail.com

Simone Costa Nunes PPGA - Pontifícia Universidade Católica de Minas Gerais sinunes@pucminas.br

Amyra Moyzes Sarsur Instituto de Sociologia da Universidade do Porto - Portugal asarsur@hotmail.com

Submissão: 01/03/2016

Aprovação: 24/11/2016 


\section{RESUMO}

O objetivo deste trabalho foi identificar a relação entre comportamentos de entrega prédefinidos para os gestores e resultados financeiros e/ou operacionais obtidos em unidades de alta performance, em uma Instituição Financeira. O questionário da pesquisa foi respondido por 241 subordinados de gestores atuantes nos cargos de Gerente, Coordenador e Supervisor. Os dados confirmaram aderência ao modelo vigente, sendo que há correlação entre o grau em que as competências são demandadas e aquilo que os gestores expressam no trabalho, conforme percepção de seus subordinados. A média das avaliações em todos os comportamentos de entrega e o índice das competências gerenciais foram superiores ao limite inferior de aceitabilidade da organização. Apesar disso, ressalta-se a necessidade de redução nos gaps de algumas competências como ação de Gestão de Pessoas. As conclusões sugerem a necessidade de adotar constantes melhorias nas práticas de gestão de pessoas para favorecer a expressão das competências gerenciais no trabalho que podem influenciar positivamente o alcance de um desempenho empresarial superior. Os resultados obtidos, bem como as análises realizadas podem servir como insumo, tanto para instituições financeiras que adotam modelos de gestão similares, como para outras organizações e para novos estudos acadêmicos.

Palavras-chave: Competências gerenciais. Gestão do desempenho. Desempenho organizacional. Gestão de pessoas. 


\begin{abstract}
The purpose of this study was to identify the relation between heads' pre-defined behaviors to deliver business results and financial and/or operational outcomes achieved in highperformance units of a financial institution. The survey conducted was answered by 241 subordinates of heads who hold the positions of Manager, Coordinator and Supervisor. Data confirm an adherence to the current model, showing a correlation between the level on which competencies are demanded by the organization and what the heads express in their work as far as their subordinates' perception is concerned. The average of evaluations of all delivery behaviors as well as the index of managerial competencies have proved to be higher than the lower acceptance limit of the organization under study. Despite of that, one must emphasize the need to reduce the gaps of some competencies through actions by the Human Resources Department. The conclusions point to the need to adopt continuing improvements of the practices developed by the Human Resources in order to promote the expression of managerial competencies in the work, which may have a positive influence on achieving a high business performance. The findings from the research as well as the analyses conducted may serve as an input not only for the financial institutions that adopt similar managerial models but also for other organizations and for new academic studies.
\end{abstract}

Keywords: Managerial Competencies. Performance Management. Business Performance. Human Resource Management. 


\section{INTRODUÇÃO}

Este trabalho tem como tema as competências gerenciais e sua mobilização, associadas ao desempenho esperado pela organização. Considerando-se que a área de gestão de pessoas deve estar alinhada à estratégia organizacional, aos anseios individuais e às demandas do contexto, a gestão do desempenho, realizada em conformidade com os modelos de gestão articulados por competências, representa uma alternativa para alcance de tal propósito, tema que vem sendo crescentemente discutido nos cenários acadêmico e empresarial (JORGE; BITTENCOURT; GALLELI, 2014). A noção de competência tem sido utilizada com frequência nas empresas sob uma perspectiva mais estratégica e também relacionada a práticas associadas à gestão de pessoas. (RUAS, 2005).

Esta pesquisa tem por objetivo identificar a relação entre os resultados financeiros e/ou operacionais obtidos nas unidades de alta performance no sistema de avaliação de uma Instituição Financeira no Brasil e a existência de gestores com comportamentos de entrega definidos no modelo de Gestão por Competências.

Os objetivos específicos do estudo são: verificar a aderência do modelo de Gestão por Competências às atribuições exercidas pelos gestores na percepção dos subordinados e relacionar com as competências apresentadas nas unidades de alta performance; analisar a relação entre as competências apresentadas pelos gerentes e os resultados financeiros e/ou operacionais; identificar possíveis gaps existentes nas competências apresentadas pelos gestores em relação àqueles presentes no modelo de Gestão por Competências, de acordo com a visão dos subordinados; e identificar as competências que se apresentam em maior nível em cada função avaliada.

As hipóteses que norteiam o estudo são: hipótese 1 - os gestores das unidades administrativas de alta performance mobilizam as competências requeridas pela organização, reforçando o pressuposto ainda não plenamente comprovado de que níveis mais altos de competência pelos empregados afetarão positivamente o desempenho organizacional (FERNANDES et al., 2013); hipótese 2 - níveis mais altos na hierarquia tendem a manifestar melhores resultados na avaliação das competências.

A organização em estudo implantou recentemente novo modelo de Gestão do Desempenho que passou a mensurar não só o cumprimento das metas financeiras e/ou operacionais previamente estabelecidas, mas também outros indicadores que têm o propósito 
de avaliar a forma como esses resultados são atingidos ou a manifestação, pelos empregados, das competências mapeadas no modelo de Gestão por Competências.

Em complemento, ressalta-se, conforme Brandão e Guimarães (2001), que tanto a gestão por competências quanto a gestão de desempenho podem estabelecer indicadores relacionados ao cumprimento de metas e outros relacionados à forma como os resultados são alcançados. A possibilidade de avaliar o desempenho sob o foco comportamental, sem perder de vista os resultados financeiros também é discutida por Leme (2006) e Fernandes (2006).

Para cumprir o objetivo proposto, a pesquisa foi realizada na Instituição Financeira Vitória (nome fictício). Ela adota modelo próprio de Gestão por Competências que tem por objetivo comunicar as competências organizacionais e individuais visando contribuir para a concretização do plano estratégico, subsidiar práticas de gestão de pessoas e orientar o desenvolvimento profissional do empregado.

Tal estudo justifica-se tendo em vista as profundas mudanças em métodos e processos pelas quais vem passando o sistema financeiro no Brasil, nos últimos anos, ampliando a demanda por trabalhadores com potencial para crescimento e capacitados para acompanhar essas transformações, gerando resultados dentro dos padrões estabelecidos pelos empregadores (BAHRY; TOLFO, 2004). Apesar desse conhecido contexto e dos diversos estudos sobre gestão por competências, muito pouco tem sido produzido a respeito da gestão por competências no setor financeiro (ROSINSKI et al., 2014).

Este artigo apresenta breve referencial teórico sobre Gestão por Competências e Gestão do Desempenho, que serviu de base para a construção do instrumento da pesquisa de campo. São também discutidos os aspectos metodológicos, bem como apresentados e discutidos os resultados do estudo. Por fim, são estabelecidas as considerações sobre a pesquisa, suas contribuições, limitações e sugestões para novos estudos. Destaca-se, neste sentido, a apresentação de análises relativas à implementação dos modelos de gestão por competências pelas organizações no Brasil, que muitas vezes o fazem sem a devida adaptação à natureza das organizações e características da ocupação laboral. Além disso, os conceitos utilizados pelas organizações para definir cada competência, nem sempre são claros o suficiente para assegurar que a avaliação corresponda à realidade da prática do avaliado. 


\section{GESTÃO POR COMPETÊNCIAS}

A abordagem sobre a temática gestão por competências percorreu os estudos que tratam da sua conceituação (DUTRA, 2008), gerenciamento das lacunas entre as competências organizacionais e estratégia (BRANDÃO; BAHRY, 2005), identificação dos profissionais mais competentes para atuar em ambientes complexos (AMORIM, 2009; BAHRY; TOLFO, 2004; FIATES; NASCIMENTO; FIATES, 2009), implantação de processos de gestão do desempenho que integrem estratégia, aprendizagem, competências e indicadores de resultados (BRANDÃO et al., 2008).

Para fins deste artigo, as competências organizacionais e funcionais não são detalhadas, apesar de se constituírem como a base para a definição das competências individuais.

Com relação às competências individuais, destaque é dado para as discussões sobre o estímulo ao desenvolvimento dos profissionais (HIPÓLITO, 2000); a mobilização das competências para gerar valor para a organização e para o empregado (ZARIFIAN, 2001); os conceitos de complexidade e espaço ocupacional, propostos por Dutra (2008); e o modelo sugerido por Ienaga (1998), que propõe a identificação de eventuais lacunas de competências da organização.

Em relação às competências gerenciais, definidas como a aplicação das capacidades individuais numa série de funções específicas, frequentemente incluindo a habilidade de liderança como premissa para o exercício do cargo (ODERICH, 2005), são destacadas as seguintes abordagens: do seu alinhamento com a estratégia empresarial (PICCHIAI; NERY, 2015); da influência da competência de gestão de equipes sobre os resultados dos empregados (FERNANDES; FLEURY; MILLS, 2006; MOHRMAN; WORLEY, 2009; RESENDE, 2000); do uso do balanced scorecard (BSC) para acompanhamento da aplicação das competências (BRANDÃO et al., 2010); da ação dos gestores sobre os comportamentos dos empregados no trabalho para assegurar o alinhamento com o pensamento estratégico (BITENCOURT, 2001; MINTZBERG; AHLSTRAND; LAMPEL, 2010); da necessidade da área de gestão de pessoas orientar seus gestores a incentivar a transformação permanente (PICCOLOTTO; VASSARI; DUTRA, 2010; QUINN et al., 2003); e do investimento dos gestores, na formação de novos líderes (ULRICH; SMALLWOOD, 2009), inclusive utilizando de gestão mais participativa (BERGAMINI, 2012). 


\section{GESTÃO DO DESEMPENHO}

A abordagem sobre a temática gestão do desempenho percorreu os estudos que tratam da associação de desempenho no trabalho ao alcance de resultados (BRANDÃO; BORGESANDRADE; GUIMARÃES, 2012; FERNANDES et al., 2006); da inclusão das competências/ações para avaliação de resultados, para além dos indicadores financeiros e econômicos (BRANDÃO et al., 2012; MOURA et al., 2009); da utilização de ferramentas de gestão de desempenho baseadas em competências, tais como o balanced scorecard (GHADIKOLAEI et al., 2011; HIPÓLITO; REIS, 2002; KAPLAN; NORTON, 1997); do uso de modelos de matriz (a exemplo da Ninebox) que cruzam o desempenho com resultados de potencial e comportamento (CARRARA, 2013; CHARAM et al., 2009; PONTES, 2010); do uso de instrumentos que procuram minimizar os efeitos subjetivos nas avaliações, como é o caso da avaliação 360 graus (WOOD; PICARELLI FILHO, 2004); das diferenças entre os conceitos de desempenho e competência, citadas por Pereira (2014); da complementaridade entre gestão de desempenho e gestão por competências, como reforçam Brandão e Guimarães (2001); da discussão proposta por Hipólito e Reis (2002) de que mais adequado é tratar do conceito de gestão de desempenho em vez de avaliação de desempenho, porque é um processo contínuo e que exige gestão; da existência de lacunas das competências individuais que viabilizarão a concretização da estratégia empresarial, a partir de avaliações que permitem mapeá-las (CARBONE et al., 2009); e de um maior comprometimento dos empregados com seu próprio autodesenvolvimento (BERGAMINI, 2012).

\section{O CASO EM ESTUDO: A Instituição Financeira Vitória}

Trata-se de uma Instituição Financeira, aqui denominada Vitória, que atua na prestação de serviços tais como financiamentos, empréstimos e poupança. Neste item são descritos o modelo de Gestão por Competências, gestão do desempenho e o sistema de avaliação de resultados financeiros e/ou operacionais da organização.

\subsection{Gestão por competências na instituição financeira Vitória}

O modelo de Gestão por Competências foi criado para facilitar o alcance da sua missão, visão e objetivos empresariais, além de subsidiá-la nas demais ações de gestão de pessoas. Ele 
foi revisado recentemente, tendo como premissa a utilização das estratégias da instituição para definir as competências e os comportamentos de entrega.

Cada competência possui comportamentos de entrega associados que irão indicar se o empregado mobiliza determinada competência. As competências e comportamentos de entrega variam em níveis de complexidade, sempre considerando o público como gestores da organização. O Quadro 1 relaciona as competências definidas no modelo e os comportamentos de entrega associados.

\section{Quadro 1 - Competências e respectivos comportamentos de entrega dos gestores}

\begin{tabular}{ll}
\hline Competência & Comportamentos \\
\hline Lidera pelo exemplo & 1. É agente de mudanças e lidera pelo exemplo. \\
& 2. Tem bom relacionamento interpessoal com clientes, parceiros e empregados. \\
& 3. Inspira as pessoas ao resguardar a imagem da empresa. \\
& 4. Contribui para um clima favorável ao alcance dos resultados. \\
Domina seus & 1. Esclarece plano de ação para a equipe com o objetivo de implantar a \\
assuntos & estratégia organizacional. \\
& 2. Recomenda mudanças nas atividades para aproveitar oportunidades. \\
& 3. Toma decisões após análise das informações relativas ao processo em que \\
& atua. \\
\hline
\end{tabular}




\section{Quadro 1 - Competências e respectivos comportamentos de entrega dos gestores}

(conclusão)

Desenvolve a si $\quad$ 1. Diagnostica e estabelece ações adequadas para seu próprio desenvolvimento mesmo e à equipe e da equipe.

2. Favorece clima harmonioso na equipe.

3. Busca autodesenvolvimento de acordo com as necessidades da sua unidade.

4. Delega atividades com responsabilidade.

5. Promove a formação de sucessores no âmbito da sua equipe.

Atua como dono da

1. Mobiliza equipe, gestor ou outras unidades visando concretização do empresa planejado, a produtividade e o controle dos custos.

2. Monitora indicadores de desempenho e solicita a participação da equipe no alcance das metas.

3. Administra de acordo com os objetivos estratégicos da unidade.

4. Pratica gestão participativa.

Foca o cliente

1. Comunica de maneira eficaz ao cliente a respeito das demandas sob sua responsabilidade.

2. Propõe soluções para atender às necessidades dos clientes.

3. Acompanha as atividades sob sua gestão e atua oportunamente visando à satisfação do cliente.

4. Percebe oportunidades no atendimento a clientes que geram impacto sobre o resultado da sua unidade.

Incentiva e pratica a $\quad$ 1. Percebe oportunidades de inovação no âmbito de sua equipe.

inovação 2. Cria ambiente propício à inovação.

3. Pratica a inovação

Fonte: Elaborado e adaptado pelos autores conforme modelo de competências da Instituição Financeira Vitória. Nota: Com a finalidade de manter sigilo quanto à identidade de instituição pesquisada, os comportamentos de entrega foram reescritos, mantendo o mesmo significado dos conteúdos originais.

\subsection{Gestão do desempenho na instituição financeira Vitória}

Acompanhando a tendência de mercado, o modelo de Gestão do Desempenho foi construído em conformidade com o planejamento estratégico e o modelo de Gestão por Competências. Em linhas gerais, a gestão do desempenho busca fomentar a cultura de responsabilização e meritocracia e promover uma gestão transparente.

O resultado final da avaliação de desempenho consiste na classificação do gestor avaliado em uma matriz de desempenho semelhante à matriz Ninebox. A avaliação é anual e a aderência dos comportamentos apresentados aos comportamentos requeridos é feita por até cinco grupos de avaliadores, sendo eles: gestor imediato, próprio empregado, pares (gestores subordinados ao mesmo gestor imediato do avaliado), grupo de relacionamento (gestores de unidade de outras áreas, não subordinadas ao avaliado, com as quais mantêm relacionamento direto) e equipe.

\section{METODOLOGIA}


A pesquisa adotou o estudo de caso único como método (EISENHARDT, 1989) e caracteriza-se como descritiva (RICHARDSON, 2010). Extraiu-se uma amostra considerando-se o tamanho da população, sendo escolhida uma regional da Vitória que abrange 408 unidades com 10.013 empregados. Foram selecionadas unidades com alta performance financeira/operacional no sistema de avaliação institucional em 2014, segundo indicadores determinados pela instituição, para testar a hipótese de existência de relação positiva entre as unidades que têm gestores com as competências esperadas e os resultados obtidos. Investigou-se no sistema de apuração mensal das metas se o resultado positivo se manteve por seis meses ou mais durante o referido ano, sendo selecionadas 39 unidades.

A empresa apresenta no modelo de Gestão por Competências três grupos de gerentes conforme o grau de complexidade exigido para o exercício do cargo. Sendo assim, optou-se por escolher somente um nível gerencial como público-alvo da avaliação para não haver diferenciação nos níveis de capacidades exigidos, sendo escolhido o grupo dos gestores de equipe (Coordenadores, Supervisores e Gerentes).

No momento da pesquisa, sendo a população de empregados lotados nas unidades de alta performance igual a 1.025 (empregados subordinados aos gestores de equipe), foi necessária uma amostra mínima de 240 avaliadores.

A coleta de dados compreendeu coleta documental representada pelo conjunto de documentos e registros da Vitória, como dados funcionais dos empregados; normativos que descrevem políticas, métodos e ferramentas de gestão de pessoas; sistemas e aplicativos internos; e indicadores de desempenho. Também foi utilizado um questionário, dividido em dois blocos, conforme descrito na sequência.

O bloco 1 apresenta a relação das seis competências presentes no modelo de Gestão por Competências. A sua finalidade é verificar a validade do modelo segundo a percepção dos subordinados dos gestores avaliados. O respondente deveria informar em que grau as competências mapeadas realmente são demandadas para o exercício da função do gestor, numa escala Likert de cinco pontos sendo: 1 (pouco demandada) e 5 (muito demandada).

O bloco 2 apresenta os comportamentos de entrega relacionados a cada uma das seis competências do modelo. Ele tem como finalidade verificar a mobilização das competências pelo gestor avaliado, conforme percepção de seus subordinados. Esse bloco contém 23 comportamentos de entrega, avaliados por meio de uma escala Likert formada por cinco pontos sendo: 1 (incipiente), 2 (emergente), 3 (eficaz), 4 (superior) e 5 (excepcional). 
Foi realizado o pré-teste desse instrumento, com sete empregados e, em seguida, foram feitos alguns ajustes conforme dúvidas e recomendações dos participantes (MARTINS; THEÓPHILO, 2009). O envio dos convites e do questionário ocorreu por meio do malote interno, em envelope lacrado e endereçado aos participantes.

Os documentos passaram por análise qualitativa-descritiva. Quanto aos questionários, a análise utilizou técnicas quantitativas, conforme explicitação das técnicas utilizadas, a seguir.

A análise fatorial foi utilizada com o objetivo de verificar se os comportamentos (bloco 2 do questionário de pesquisa) poderiam ser reduzidos às seis competências gerenciais mapeadas pela instituição (bloco 1 do questionário de pesquisa).

Foi realizado o teste de adequação da amostra (Kaiser-Meyer-Olkin-KMO), bem como o teste de esfericidade de Bartlett (MALHOTRA, 2006). Também foi avaliada a unidimensionalidade de cada uma das competências envolvidas no modelo bem como o nível de consistência interna por meio do Alfa de Cronbach. A validade convergente foi avaliada por meio do uso da variância extraída (AVE). A Tabela 1 apresenta esses resultados.

\section{Tabela 1 - Medidas KMO, Barlett, variância extraída e alfa de Cronbach}

\begin{tabular}{lcccc}
\hline \multicolumn{1}{c}{ Competências gerenciais } & KMO & Bartlett & $\begin{array}{c}\text { Variância } \\
\text { Extraída (\%) }\end{array}$ & $\begin{array}{c}\text { Alfa de } \\
\text { Cronbach }\end{array}$ \\
\hline Lidera pelo exemplo & 0,772 & 0,000 & 74,7 & 0,886 \\
Domina seus assuntos & 0,720 & 0,000 & 74,4 & 0,827 \\
Desenvolve a si mesmo e à equipe & 0,881 & 0,000 & 73,1 & 0,907 \\
Atua como dono da empresa & 0,838 & 0,000 & 77,6 & 0,902 \\
Foca o cliente & 0,825 & 0,000 & 79,7 & 0,915 \\
Incentiva e pratica a inovação & 0,765 & 0,000 & 87,4 & 0,928 \\
\hline
\end{tabular}

Fonte: Elaborado pelos autores.

Todas as competências se mostraram unidimensionais (possuem apenas um fator extraído). Concluiu-se, por meio da análise fatorial, que os comportamentos de entrega constantes no bloco 2 do questionário de pesquisa podem ser reduzidos às seis competências gerenciais relacionadas no bloco 1 do questionário, de acordo com o modelo de competências vigente na organização em estudo.

Em seguida, foram realizadas as estatísticas descritivas (médias e desvio-padrão) das notas atribuídas pelos respondentes nos blocos 1 e 2 do questionário. A técnica Chi-Square Automatic Interaction Detector (CHAID) foi utilizada para comprovar a existência de diferenças significativas entre as competências gerenciais e a função gratificada exercida pelo gestor avaliado.

A análise de cluster teve por objetivo agrupar os respondentes de acordo com as avaliações realizadas para as seis competências. Posteriormente, aplicou-se novamente a 
técnica CHAID, para investigar a existência de relacionamentos entre os grupos criados, por meio da análise de cluster e o nível hierárquico do gestor avaliado. Todavia, nenhuma diferença significativa foi detectada.

Para identificar o grau de relacionamento entre o nível em que as competências mapeadas são demandadas e a efetiva manifestação dos comportamentos associados a essas competências pelos gestores, foi realizada a análise de correlação. Por fim, o índice geral das competências entregues foi obtido a partir do emprego da técnica de modelagem de equações estruturais.

\section{RESULTADOS E DISCUSSÃO}

Para revalidação da escala e sua dimensionalidade para o contexto proposto, optou-se pela análise fatorial, que avaliou a unidimensionalidade de cada uma das seis competências do modelo, bem como o nível de consistência interna por meio do Alfa de Cronbach (MALHOTRA, 2006).

Concluiu-se que os comportamentos de entrega constantes no bloco 2 do questionário podem ser reduzidos às seis competências gerenciais relacionadas no bloco 1 , conforme 0 modelo de Gestão por Competências da Instituição Vitória.

\subsection{Resultados e análises das estatísticas descritivas}

Do conjunto de gestores avaliados, 56,8\% eram Coordenadores, 24,9\% Supervisores e $18,3 \%$ Gerentes, num total de 241 avaliações.

A análise da aderência do modelo de Gestão por Competências foi realizada a partir dos itens do bloco 1 do questionário. Se a média das notas atribuídas a cada competência fosse igual ou superior a três, considerava-se que a competência em avaliação realmente era exigida para o exercício das funções gratificadas dos gestores de equipe.

A Tabela 2 apresenta a média aritmética e o desvio-padrão com a finalidade de apurar o grau médio de concordância dos respondentes em relação a cada item e a distribuição das respostas em torno da média calculada. Quanto maior a média, maior a aderência da competência para o exercício das atividades do gestor avaliado. 
Tabela 2 - Aderência do modelo de competências

\begin{tabular}{llllll}
\hline Competências Gerenciais & N & Mínimo & Máximo & Média & Desvio-Padrão \\
\hline Lidera pelo exemplo & 241 & 1 & 5 & 4,1 & 1,1 \\
Domina seus assuntos & $\mathbf{2 4 1}$ & $\mathbf{1}$ & $\mathbf{5}$ & $\mathbf{4 , 3}$ & $\mathbf{1 , 0}$ \\
Desenvolve a si mesmo e à equipe & 241 & 1 & 5 & 3,9 & 1,1 \\
Atua como dono da empresa & 241 & 1 & 5 & 3,9 & 1,3 \\
Foca o cliente & $\mathbf{2 4 1}$ & $\mathbf{1}$ & $\mathbf{5}$ & $\mathbf{4 , 3}$ & $\mathbf{1 , 0}$ \\
Incentiva e pratica a inovação & 241 & 1 & 5 & 3,7 & 1,2 \\
\hline
\end{tabular}

Fonte: Elaborado pelos autores.

Considerando o critério definido para constatar a aderência do modelo de Gestão por Competências, pode-se dizer que os avaliadores entendem que as competências estabelecidas no modelo da instituição realmente são demandadas para o exercício das funções em análise, pois a média das notas em todas as competências foi superior a três, com destaque para as competências Domina seus assuntos e Foca o cliente. Se todas as competências são demandadas, considera-se também que os gestores deverão mobilizá-las em alto nível no exercício de suas atividades, pois o alinhamento entre as competências mapeadas e aquelas expressas pelos gestores representa um recurso importante para que a organização tenha vantagem competitiva, conforme discute Dutra (2008).

É possível perceber também o nível de variabilidade das respostas em torno da média por meio do cálculo do desvio-padrão. Houve razoável dissenso entre as avaliações das competências Atua como dono da empresa e Incentiva e pratica a inovação, indicando que alguns empregados avaliaram essas competências como muito demandadas, enquanto outros as classificaram como pouco demandadas para a função avaliada.

\subsection{Análise em relação às competências e aos comportamentos de entrega}

No conjunto de respostas, o comportamento mais bem avaliado, observando-se todas as competências e com pouca variabilidade nas respostas, foi Tem bom relacionamento interpessoal com clientes, parceiros e empregados, que compõe a competência Lidera pelo exemplo. Estabelecer bom relacionamento interpessoal foi descrita como uma das competências mais importantes para que os executivos possam responder às exigências do mercado globalizado, no entendimento de Echeveste et al. (1999). Sendo assim, esse pode ser considerado um ponto forte da organização em estudo, o que também confirma sua vocação de prestação de serviços e relacionamento com os clientes como pontos fortes em sua história.

Ao observar cada uma das seis competências, alguns resultados destacam-se: 


\section{- Competência Lidera pelo exemplo (Tabela 3)}

O comportamento de entrega É agente de mudanças e lidera pelo exemplo obteve a menor média entre os comportamentos desta competência. Assim, considera-se importante promover ações para desenvolver esse comportamento porque os gestores devem identificar oportunidades no ambiente, incluir ou melhorar os processos com os quais atuam, visando alcançar a estratégia definida pela empresa (MOHRMAN; WORLEY, 2009). Não obstante, infere-se que, sendo essa uma instituição financeira que segue padrões rígidos em suas normativas e procedimentos, inclusive por responder a auditorias e precisar preservar a qualidade dos serviços, a compreensão sobre o tema mudança pode ser enviesada, gerando comportamentos de repetição, em vez de comportamentos inovadores.

\section{Tabela 3 - Comportamentos da competência Lidera pelo exemplo}

\begin{tabular}{llllll}
\hline Comportamentos de entrega & N & Mínimo & Máximo & Média & Desvio-Padrão \\
\hline É agente de mudanças e lidera pelo exemplo & 241 & 1 & 5 & 3,4 & 1,2 \\
Tem bom relacionamento interpessoal com clientes, 241 & 1 & 5 & 4,0 & 1,0 \\
parceiros e empregados & & & & & \\
Inspira as pessoas ao resguardar a imagem da empresa & 241 & 1 & 5 & 3,8 & 1,1 \\
$\begin{array}{l}\text { Contribui para um clima favorável ao alcance dos } \\
\text { resultados }\end{array}$ & & & &
\end{tabular}

Fonte: Elaborado pelos autores.

\section{- Competência Domina seus assuntos (Tabela 4)}

A menor média foi atribuída ao comportamento de entrega Esclarece plano de ação para a equipe com o objetivo de implantar a estratégia organizacional. Sugere-se atenção a esse fator, pois o gestor tem o papel fundamental de facilitar o entendimento dos empregados quanto aos objetivos a serem alcançados. (REZENDE, 2003). Além disso, é o gestor quem deve assegurar que os comportamentos no trabalho estejam em conformidade com o pensamento estratégico (MINTZBERG; AHLSTRAND; LAMPEL, 2010).

Tabela 4 - Comportamentos da competência Domina seus assuntos

\begin{tabular}{llllll}
\hline Comportamentos de entrega & $\mathbf{N}$ & Mínimo & Máximo & Média & Desvio-Padrão \\
\hline $\begin{array}{l}\text { Esclarece plano de ação para a equipe com o } \\
\text { objetivo de implantar a estratégia organizacional }\end{array}$ & 1 & 5 & 3,4 & 1,2 \\
$\begin{array}{l}\text { Recomenda mudanças nas atividades para } \\
\text { aproveitar oportunidades }\end{array}$ & 1 & 5 & 3,5 & 1,2 \\
$\begin{array}{l}\text { Toma decisões após análise das informações } \\
\text { relativas ao processo em que atua }\end{array}$ & 1 & 5 & 3,9 & 1,1 \\
\hline
\end{tabular}

Fonte: Elaborado pelos autores.

\section{- Competência desenvolver a si mesmo e à equipe (Tabela 5)}

A média atribuída ao comportamento de entrega Diagnostica e estabelece ações adequadas para seu próprio desenvolvimento e da equipe foi bem próxima da nota mínima, 
indicando a necessidade de intervenção no sentido de melhorar a atuação dos gestores. Isso porque é importante que eles estejam atentos a situações de aprendizagem, bem como à promoção de ações voltadas para o desenvolvimento de competências (BITENCOURT, 2001). De forma similar, na pesquisa realizada por Kouzes e Posner (2010), a competência Capacitar pessoas foi apresentada como uma entre as cinco práticas relevantes em atividades de gestão. Infere-se que, como as atividades da Instituição Financeira são rotineiras e seguem padrões pré-definidos, o nível de conscientização dos gestores sobre a necessidade de desenvolvimento constante não é alto, já que historicamente, eles próprios aprenderam a atividade no seu cotidiano e ascenderam sem necessidade de aprimoramento intenso.

O comportamento Promove a formação de sucessores no âmbito da sua equipe foi o comportamento de entrega com menor média nesse conjunto, o que ratifica a não preocupação com a formação e estabelecimento de novos desafios aos subordinados. É preciso pensar em formas de desenvolvimento desse comportamento, pois é essencial que os gestores invistam na próxima geração de líderes, conforme reforçado por Ulrich e Smallwood (2009).

Tabela 5 - Comportamentos da competência Desenvolve a si mesmo e à equipe

\begin{tabular}{|c|c|c|c|c|c|}
\hline Comportamentos de entrega & $\mathbf{N}$ & Mínimo & Máximo & Média & Desvio-Padrão \\
\hline $\begin{array}{l}\text { Diagnostica e estabelece ações adequadas para seu } \\
\text { próprio desenvolvimento e da equipe }\end{array}$ & 241 & 1 & 5 & 3,3 & 1,2 \\
\hline Favorece clima harmonioso na equipe & 241 & 1 & 5 & 3,6 & 1,3 \\
\hline $\begin{array}{l}\text { Busca autodesenvolvimento de acordo com as } \\
\text { necessidades da sua unidade }\end{array}$ & 241 & 1 & 5 & 3,6 & 1,2 \\
\hline Delega atividades com responsabilidade & 241 & 1 & 5 & 3,6 & 1,1 \\
\hline $\begin{array}{l}\text { Promove a formação de sucessores no âmbito da } \\
\text { sua equine }\end{array}$ & 241 & 1 & 5 & 3,2 & 1,3 \\
\hline
\end{tabular}

Fonte: Elaborado pelos autores.

\section{- Competência Atua como dono da empresa (Tabela 6)}

A avaliação desta competência mostrou-se satisfatória, mas é relevante mencionar a necessidade de reduzir a lacuna dessa competência gerencial, pois o gestor exerce o importante papel de direcionar a gestão eficiente e eficaz dos recursos (WOOD; PICARELLI FILHO, 2004). Nesse sentido, solicitar a participação da equipe no alcance das metas é um comportamento relevante considerando-se que a gestão de equipe é fundamental para viabilizar a consecução dos objetivos por meio das pessoas (MOHRMAN; WORLEY, 2009). Além disso, o ambiente pressiona as organizações a atenderem à exigência de um novo perfil de empregado que participe da operacionalização da estratégia (ROSINSKI et al., 2014). 
A prática da gestão participativa obteve média igual a 3,4 e representa um ponto de atenção, porque essa prática pode melhorar a satisfação dos empregados e tornar o ambiente de trabalho mais harmonioso, de acordo com Bergamini (2012).

Tabela 6 - Comportamentos da competência Atua como dono da empresa

\begin{tabular}{llllll}
\hline Comportamentos de entrega & N & Mínimo & Máximo & Média & Desvio-Padrão \\
\hline $\begin{array}{l}\text { Mobiliza equipe, gestor ou outras unidades visando à } \\
\text { concretização do planejado, à produtividade e ao }\end{array}$ & 241 & 5 & 3,4 & 1,2 \\
$\begin{array}{l}\text { controle de custos } \\
\begin{array}{l}\text { Monitora indicadores de desempenho e solicita a } \\
\text { participação da equipe no alcance das metas }\end{array}\end{array}$ & 1 & 5 & 3,7 & 1,1 \\
$\begin{array}{l}\text { Administra de acordo com os objetivos estratégicos } \\
\text { da unidade }\end{array}$ & 241 & 1 & 5 & 3,7 & 1,1 \\
Pratica gestão participativa & 241 & 1 & 5 & 3,4 & 1,2 \\
\hline
\end{tabular}

Fonte: Elaborado pelos autores.

\section{- Competência Foca o cliente (Tabela 7)}

Observa-se que a média das notas atribuídas foi superior a três. A ferramenta BSC apresenta o cliente entre as quatro perspectivas que contribuem de forma efetiva para o alcance dos objetivos organizacionais (KAPLAN; NORTON, 1997). Na pesquisa realizada por Brandão et al. (2010), constatou-se que a maior média atribuída pelos gestores na autoavaliação foi para a competência gerencial relacionada ao atendimento das necessidades e expectativas dos clientes, representando um indicador da relevância dessa competência para gestores de instituições financeiras. Além disso, todos os comportamentos relacionados à perspectiva clientes foram mencionados pelos gestores nas entrevistas realizadas pelos mesmos autores, reforçando a importância dessa competência para o desempenho. Sendo assim, desenvolver comportamentos dessa competência poderá aumentar as possibilidades de alcançar os resultados estabelecidos no planejamento estratégico da organização.

Tabela 7 - Comportamentos da competência Foca o cliente

\begin{tabular}{llllll}
\hline Comportamentos de entrega & N & Mínimo & Máximo & Média & Desvio-Padrão \\
\hline $\begin{array}{l}\text { Comunica de maneira eficaz ao cliente a respeito } \\
\text { das demandas sob sua responsabilidade }\end{array}$ & 1 & 5 & 3,8 & 1,1 \\
$\begin{array}{l}\text { Propõe soluções para atender às necessidades dos } \\
\text { clientes }\end{array}$ & 1 & 5 & 3,8 & 1,0 \\
$\begin{array}{l}\text { Acompanha as atividades sob sua gestão e atua } 241 \\
\text { oportunamente visando à satisfação do cliente }\end{array}$ & 5 & 3,7 & 1,1 \\
$\begin{array}{l}\text { Percebe oportunidades no atendimento a clientes } 241 \\
\text { que geram impacto sobre o resultado da sua } \\
\text { unidade }\end{array}$ & & 5 & 3,6 & 1,2 \\
\hline
\end{tabular}

Fonte: Elaborado pelos autores.

\section{- Competência Incentiva e pratica a inovação (Tabela 8)}


Apesar de essa competência representar um dos papéis desafiadores do gestor, que deve conviver e gerenciar mudanças e ter pensamento criativo (QUINN et al., 2003), a menor média entre todos os comportamentos de entrega constantes no modelo foi para o item Cria ambiente propício à inovação. $\mathrm{O}$ gestor deve ser capaz de mobilizar as equipes com o propósito de promover a inovação e competitividade nas empresas para aumentar as possibilidades de se manter sustentável num ambiente de constantes mudanças, argumenta Pereira (2014).

Tabela 8 - Comportamentos da competência Incentiva e pratica a inovação

\begin{tabular}{llllll}
\hline Comportamentos de entrega & N & Mínimo & Máximo & Média Desvio-Padrão \\
\hline $\begin{array}{l}\text { Percebe oportunidades de inovação no âmbito de sua } \\
\text { equipe }\end{array}$ & 241 & 1 & 5 & 3,3 & 1,2 \\
$\begin{array}{l}\text { Cria ambiente propício à inovação } \\
\text { Pratica a inovação }\end{array}$ & 241 & 1 & 5 & 3,1 & 1,2 \\
\hline
\end{tabular}
Fonte: Elaborado pelos autores.

\subsection{Análise dos Resultados Relativos à Mobilização das Competências}

O critério utilizado para considerar que um gestor mobiliza as competências definidas no modelo da organização foi a obtenção de média igual ou superior a três, em todas as competências constantes no modelo. Pode-se dizer que a hipótese 1 desta pesquisa foi confirmada, pois os gestores de equipe das unidades de alta performance foram avaliados com nota superior a três em todos os comportamentos de entrega associados a cada uma das seis competências constantes no modelo da empresa. Esse achado corrobora a pesquisa realizada por Cockerill (1994), que associou a manifestação de competências gerenciais relevantes ao desempenho obtido nas unidades gerenciadas pelos participantes da pesquisa.

As médias das notas atribuídas após o agrupamento dos 23 comportamentos de entrega a cada uma das seis competências mapeadas pela organização encontram-se na Tabela 9. Após o agrupamento, é possível perceber que houve pouca variabilidade nas respostas por meio do cálculo do desvio-padrão.

Tabela 9 - Competências gerenciais

\begin{tabular}{llllll}
\hline Competências gerenciais & N & Mínimo & Máximo & Média & Desvio-Padrão \\
\hline Lidera pelo exemplo & 241 & 1,0 & 5,0 & 3,7 & 1,0 \\
Domina seus assuntos & 241 & 1,0 & 5,0 & 3,6 & 1,0 \\
Desenvolve a si mesmo e à equipe & 241 & 1,0 & 5,0 & 3,4 & 1,0 \\
Atua como dono da empresa & 241 & 1,0 & 5,0 & 3,6 & 1,0 \\
Foca o cliente & 241 & 1,3 & 5,0 & 3,7 & 1,0 \\
Incentiva e pratica a inovação & 241 & 1,00 & 5,0 & 3,2 & 1,1 \\
\hline
\end{tabular}

Fonte: Elaborado pelos autores. 
A média das avaliações reforça a relação positiva entre manifestação das competências mapeadas pela organização e o desempenho, tendo em vista que a amostra é composta somente de unidades com alta performance no sistema de avaliação institucional.

Considerando a argumentação de Piccolotto, Vassari e Dutra (2010) sobre a importância de a área de gestão de pessoas orientar seus gestores a incentivar a transformação aumentando as chances de a empresa manter-se competitiva no mercado, destaca-se então a necessidade de ações no sentido de desenvolver a competência Incentiva e pratica a inovação, que teve a menor média entre todas as competências gerenciais avaliadas. A complexidade do setor financeiro e a necessidade de observar diversas normas internas e externas com a finalidade de mitigar os riscos da atividade pode ser uma explicação para o resultado encontrado, pois os empregados tenderiam a impor limites à inovação nos processos.

Também foi realizada análise segregando os dados relativos a cada uma das três funções pertencentes ao grupo de gestores de equipe para verificar existência de diferenças significativas na manifestação das competências de acordo com esse critério. A manifestação da competência Incentiva e pratica a inovação foi avaliada com média muito próxima do limite inferior de aceitabilidade e essa foi considerada a competência menos demandada nas três funções, na percepção dos subordinados. Frente a esse resultado, sugere-se que os gestores busquem favorecer um clima propício à criatividade, disseminando uma cultura receptiva às mudanças, para que as equipes também percebam a relevância dessa atitude e pratiquem a inovação nos processos em que atuam.

Foi utilizada a técnica CHAID para a avaliação da existência de diferenças significativas entre o nível em que as competências são demandadas e a função gratificada exercida pelo gestor (KASS, 1980).

Ao se avaliar o relacionamento das seis competências com a função gratificada exercida pelo gestor avaliado, a única diferença significativa detectada foi a exigência percebida pelos avaliadores da competência Domina seus assuntos. Gestores com cargo executivo mais baixo (Supervisores e Coordenadores) deveriam mobilizar essa competência em grau superior aos Gerentes na percepção dos respondentes (4,416 contra 3,977 de gestores com nível hierárquico mais alto). Provavelmente os respondentes esperam que os empregados que exercem as funções gerenciais iniciais tenham mais conhecimento operacional das atividades sob sua supervisão ou coordenação e, na medida em que a complexidade aumenta, outras competências sejam demandadas em nível superior. 


\subsection{Análise dos achados comparando-se o nível hierárquico dos gestores}

De forma a avaliar a existência de algum relacionamento entre os grupos criados com a análise de cluster e o nível hierárquico do gestor avaliado, foi utilizada a técnica CHAID. Todavia, nenhuma diferença significativa foi detectada. Esperava-se que as notas médias recebidas para as competências do cargo de Gerentes e Coordenadores fossem superiores às mensuradas para o cargo de Supervisão, pois quanto maior o nível hierárquico, maior deveria ser o nível de desenvolvimento do empregado nas competências gerenciais. No entanto, os dados deste estudo mostram a inexistência de diferenças nas avaliações considerando a função exercida.

Reduzido percentual dos gestores de equipe avaliados (menos de $20 \%$ em todos os níveis hierárquicos) obteve notas baixas nas avaliações, o que pode ser interpretado como ponto positivo. Considerando-se que as funções pertencem a níveis hierárquicos diferentes, esperava-se que o percentual de notas médias ou altas fosse maior nas funções de Coordenador e Gerentes, mas não foram registradas diferenças significativas entre os percentuais mencionados.

Sendo assim, os dados revelam mais necessidade de desenvolvimento dos gestores que exercem funções de nível hierárquico superior dentro do grupo de funções estudadas, pois espera-se que as médias das notas referentes à manifestação dos comportamentos de entrega sejam maiores para os Gerentes em relação aos Coordenadores, que por sua vez deveriam ser maiores do que as médias atribuídas aos Supervisores. Mas, isso não foi observado.

\subsection{Análise de correlação entre o nível de demanda e a mobilização das competências gerenciais}

Confirmada a aderência do modelo de competências vigente na organização, conforme percepção dos subordinados dos gestores avaliados, buscou-se analisar a relação entre o nível em que as competências são demandadas (dados do bloco 1) e a efetiva manifestação dos comportamentos a elas associados (dados do bloco 2).

Para atingir esse propósito, foi usado o índice de correlação de Pearson, sendo que valores próximos de -1 indicam alta correlação negativa, valores próximos de zero indicam ausência de correlação e valores próximos de 1 significam alta correlação positiva (SOARES; 
FARIAS; CESAR, 2002). Existe relacionamento positivo entre todas as competências e o nível em que elas são demandadas na percepção dos avaliadores.

Foi realizado também teste de hipóteses para verificar se tal correlação é significativamente diferente de zero. A interpretação da análise dos resultados da correlação é que existe correspondência entre o que se espera que o gestor apresente e a efetiva mobilização dos comportamentos de entrega, segundo a percepção dos subordinados dos gestores de equipe avaliados na Instituição Financeira Vitória.

\subsection{Obtenção do índice geral de competências entregues}

Para obtenção do índice geral de entrega das competências gerenciais, empregou-se a técnica de modelagem de equações estruturais. Conforme proposto por Hair et al. (2005), tal técnica permite representar conceitos não observados e estimar múltiplas e inter-relacionadas relações de dependência em sua utilização.

O menor coeficiente de relacionamento encontrado foi para a competência Incentiva e pratica a inovação, confirmando a necessidade de atuação da empresa na promoção do desenvolvimento dos gestores.

Para verificar a significância dos coeficientes estimados, foi obtida estimativa de valores t utilizando a técnica bootstrap com 241 casos. Os resultados encontrados (todos acima de 1,96) atestaram que os coeficientes são significativos.

Para a validação do modelo, a primeira etapa constitui a avaliação do modelo de mensuração. O primeiro critério a ser avaliado é a confiabilidade da consistência interna. De acordo com Henseler, Ringle e Sinkowics (2009), após a avaliação da confiabilidade do modelo de mensuração, é importante avaliar sua validade. Nesse sentido, dois subtipos são usualmente verificados: validade convergente e validade discriminante. Para analisar a validade convergente, Fornell e Larcker (1981) sugerem o uso da variância extraída (AVE), indicando que deve ter o valor mínimo de 0,5 . A variância extraída dos fatores variou de 74,4 a $87,4 \%$, indicando boa representatividade. Todas as competências se mostraram unidimensionais (possuem apenas um fator extraído) e com Alfa de Cronbach superior a 0,5. Em relação às cargas fatoriais, conforme Hair et al. (2005), aquelas acima de 0,3 atingem o nível mínimo, cargas fatoriais de 0,4 são mais importantes e as maiores que 0,5 são consideradas estatisticamente significativas. Em todos os comportamentos, as cargas fatoriais se mostraram estatisticamente significativas. 
A média encontrada foi de 3,6 e, apesar de a média das competências gerais ter sido superior ao limite mínimo definido pela Instituição Financeira Vitória, como mobilização eficaz das competências por parte dos gestores, faz-se necessário que a organização atue no sentido de reduzir a lacuna de desenvolvimento, como sugere Ienaga (1998). O mesmo autor alerta sobre a importância de gerir as competências constantemente para impedir o crescimento da lacuna em decorrência do aumento da complexidade do ambiente externo ou pela obsolescência das competências mapeadas pela organização.

Destaca-se a necessidade de desenvolvimento das competências gerenciais para aumentar as chances de a organização apresentar vantagem competitiva sustentável. Isso pode ser explicado com a opinião de King, Fowler e Zeithami (2002) de que a identificação dessa lacuna possibilita aos gestores conhecer as áreas que necessitam de investimento, com a finalidade de gerenciar as competências resultantes da sinergia das capacidades individuais existentes na empresa (FIATES et al., 2009).

\section{CONSIDERAÇÕES FINAIS}

O estudo teve como objetivo identificar a relação entre os resultados financeiros e/ou operacionais obtidos nas unidades consideradas de alta performance no sistema de avaliação da organização e a existência de gestores de equipe com os comportamentos de entrega definidos no modelo de gestão.

Antes de investigar essa relação, considerou-se importante conhecer a percepção dos subordinados dos gestores de equipe sobre a aderência das competências mapeadas pela Instituição Financeira Vitória em seu modelo de Gestão por Competências para o exercício das atividades inerentes às funções gratificadas em análise e seu relacionamento com as competências apresentadas. Os dados resultantes da pesquisa confirmam a aderência ao modelo proposto pela organização na percepção dos subordinados dos gestores avaliados, sendo que há correspondência entre o que se espera que o gestor apresente e a mobilização manifestada.

Para investigar a hipótese de existência de relação positiva entre competência e desempenho, partiu-se da suposição de que os gestores de equipe das unidades consideradas como de alta performance apresentavam as competências requeridas.

Por meio do segundo bloco do questionário, respondentes puderam avaliar se seus respectivos gestores realmente apresentavam as competências mapeadas pela organização. Os 
dados confirmam a relação positiva entre a mobilização das competências e o desempenho organizacional, pois o resultado obtido para o índice geral das competências bem como a média obtida em cada um dos comportamentos de entrega associados às seis competências são superiores ao que a Instituição Financeira Vitória considera satisfatório no modelo de Gestão por Competências.

Apesar da confirmação da relação positiva entre competência e desempenho encontrada nesta pesquisa, a empresa precisa adotar práticas de gestão de pessoas que viabilizem a diminuição dos gaps existentes nas competências gerenciais apresentadas, tendo em vista que o índice geral e a média das notas atribuídas pelos subordinados na manifestação dos comportamentos encontram-se muito próximos do limite inferior considerado satisfatório pela organização estudada, em especial as competências Desenvolve a si mesmo e à equipe e Incentiva e pratica a inovação. Como o novo modelo de Gestão de Desempenho, implantado em 2014, passou a considerar ações (comportamentos), além do alcance dos resultados financeiros, espera-se que a avaliação da mobilização dos comportamentos de entrega para alcançar as metas estabelecidas incentive a busca pelo desenvolvimento das competências.

Quanto ao objetivo específico que trata da identificação das competências que se apresentam em maior nível em cada função gratificada, a análise partiu do pressuposto de que os diferentes níveis hierárquicos incluídos no grupo de gestores de equipe manifestam as competências em diferentes graus de desenvolvimento, conforme a exigência da função exercida.

Essa hipótese não é confirmada pelos dados obtidos, pois nenhuma diferença significativa foi detectada. A única diferença significativa encontrada foi em relação ao nível em que a competência Domina seus assuntos é demandada na opinião dos avaliadores e não em relação à manifestação da competência. Além disso, na percepção dos respondentes, os gestores em cargo executivo em nível menos elevado (Supervisores e Coordenadores) deveriam mobilizar essa competência em maior nível.

Os dados revelam a necessidade de desenvolvimento dos gestores que exercem funções de nível hierárquico superior dentro do grupo de funções estudadas, pois as médias das notas referentes à manifestação dos comportamentos de entrega deveriam ser maiores para os Gerentes em relação aos Coordenadores que, por sua vez, deveriam ser maiores do que as médias atribuídas aos Supervisores, o que não foi observado.

Como limitações do estudo destacam-se: a impossibilidade de comparação entre unidades de alta performance e unidades de baixa performance, na instituição Vitória; a 
seleção de um único grupo de gestores da instituição como público-alvo da pesquisa; a realização da avaliação somente pelos subordinados; e a utilização de amostra pertencente apenas a uma organização, restringindo a possibilidade de generalizações dos resultados a outros contextos organizacionais.

Nesse sentido, recomenda-se a realização de outros estudos sobre o tema com vistas a corroborar ou não a relação entre competência e desempenho, para correlacionar os achados e conclusões com os encontrados neste estudo.

As conclusões deste estudo sugerem a necessidade de adotar constantes melhorias nas práticas de gestão de pessoas para favorecer a expressão das competências gerenciais no trabalho que podem influenciar positivamente o alcance de um desempenho empresarial superior em termos de qualidade e produtividade. Os resultados obtidos, bem como as análises realizadas podem servir como insumo, tanto para instituições financeiras que adotam modelos de gestão similares, como para outras organizações e para novos estudos acadêmicos, considerando que revelam dados e informações da realidade empresarial. 


\section{REFERÊNCIAS}

AMORIM, T. N. G. F. Gestão de pessoas no agronegócio. In: CALLADO, A. A. C. (org.). Agronegócio. 2. ed. São Paulo: Atlas, 2009.

BAHRY, C. P.; TOLFO, S. R. A gestão de competências e a obtenção de vantagem competitiva sustentável em organizações bancárias. Revista de Administração Mackenzie, São Paulo, v. 5, n. 2, p. 37-54, jul./dez. 2004.

BERGAMINI, C. W. Competência: a chave do desempenho. São Paulo: Atlas, 2012.

BITENCOURT, C. C. A gestão de competências gerenciais: a contribuição da aprendizagem organizacional. Tese (Doutorado). Universidade Federal do Rio Grande do Sul. Escola de Administração. Programa de Pós-Graduação em Administração. Porto Alegre, 2001.

BRANDÃO, H. P.; BAHRY, C. P. Gestão por competências: métodos e técnicas para mapeamento de competências. Revista do Serviço Público, Brasília, v. 56, n. 2, p. 179-194, abr./jun. 2005.

BRANDÃO, H. P.; BORGES-ANDRADE, J. E.; GUIMARÃES, T. A. Desempenho organizacional e suas relações com competências gerenciais, suporte organizacional e treinamento. RAUSP - Revista de Administração, São Paulo, v. 47, n. 4, p. 523-539, out./nov./dez. 2012.

BRANDÃO, H. P. et al. Desempenho e estrutura interna de uma escala de competências gerenciais. Psicologia: Teoria e Pesquisa, Brasília, v. 26 n. 1, p. 171-182, jan./mar. 2010.

BRANDÃO, H. P. et al. Relationships between learning, context and competency: a multilevel study. BAR - Brazilian Administration Review, Rio de Janeiro, v. 9, n. 1, p. 122, Jan./Mar. 2012.

BRANDÃO, H. P.; GUIMARÃES, T. A. Gestão de competências e gestão de desempenho: tecnologias distintas ou instrumentos de um mesmo construto? RAE - Revista de Administração de Empresas, São Paulo, v. 41, n. 1, p. 8-15, jan./ mar. 2001.

BRANDÃO, H. P. et al. Gestão de desempenho por competências: integrando a gestão por competências, o balanced scorecard e a avaliação 360 graus. Revista de Administração Pública, Rio de Janeiro, v. 42, n. 5, p. 875-898, set./out. 2008.

CARBONE, P. P. et al. Gestão por competências e gestão do conhecimento. 3. ed. Rio de Janeiro: FGV, 2009.

CHARAM, R. et al. Pipeline de liderança: o desenvolvimento de líderes como diferencial competitivo. Rio de Janeiro: Elsevier, 2009.

CARRARA, T. M. P. Retenção de talentos de diversas gerações em um mesmo contexto organizacional: um estudo em empresa de grande porte da indústria do aço. Dissertação (Mestrado). Pontifícia Universidade Católica de Minas Gerais. Programa de Pós-graduação em Administração. Belo Horizonte, 2013.

COCKERILL, T. The king of competence for rapid change. In: MABEY, C.; ILES, P. (orgs.). Managing learning. London: Routledge, 1994. p. 70-76.

DUTRA, J. S. Competências: conceitos e instrumentos para a gestão de pessoas na empresa moderna. São Paulo: Atlas, 2008. 
ECHEVESTE, S. et al. Perfil do executivo no mercado globalizado. Revista de Administração Contemporânea, v. 3, n. 2, p. 167-186, maio/ago. 1999.

EISENHARDT, K. M. Building theories from case study research. The Academy of Management Review, v. 14, n. 4, p. 532-550, out. 1989.

FERNANDES, B. H. R. Competências e desempenho organizacional: o que há além do Balanced Scorecard. São Paulo: Saraiva, 2006.

FERNANDES, B. H. R.; FLEURY, M. T. L.; MILLS, J. Construindo o diálogo entre competência, recursos e desempenho organizacional. RAE - Revista de Administração de Empresas, São Paulo, v. 46, n. 4, p. 48-65, out./nov./dez. 2006.

FERNANDES, B. H. R. et al. Os impactos das percepções e atitudes dos funcionários sobre a produtividade e a qualidade em empresas de manufatura. BASE - Revista de Administração e Contabilidade da Unisinos, São Leopoldo, v. 10, n. 3, p. 254-272, jul./set. 2013.

FIATES, G. G. S.; NASCIMENTO, A. D. R.; FIATES, J. E. A. Uma estratégia para a gestão de pessoas em organizações de conhecimento: uma experiência da gestão de competências em um instituto de pesquisa e desenvolvimento. Estratégia e Negócios, Florianópolis, v. 2, n. 1, p.158-178, jan./jun. 2009.

FORNELL, C.; LARCKER, D. F. Evaluating structural equation models with unobservable variables and measurement error. Journal of Marketing Research, v. 18, n. 1, p. 39-50, fev. 1981.

GHADIKOLAEI, A. S. et al. Cause and effect relations of bsc in universities of Iran. International Journal of Management and Innovation, v. 3, n. 2, p. 16-25, 2011.

HAIR, J. F. et al. Análise multivariada de dados. Porto Alegre: Bookman, 2005.

HENSELER, J.; RINGLE, C. M.; SINKOWICS, R. R. The use of partial least squares path modeling in international marketing. Advances in International Marketing, v. 20, p. 277 319, 2009.

HIPÓLITO, J. A. M. Competências e níveis de complexidade do trabalho como parâmetros orientadores de estruturas salariais. In: ENCONTRO DA ASSOCIAÇÃO NACIONAL DE PÓS-GRADUAÇÃO E PESQUISA EM ADMINISTRAÇÃO, 24., 2000, Florianópolis, SC. Anais... Rio de Janeiro: ANPAD, 2000.

HIPÓLITO, J. A. M.; REIS, G. G. A avaliação como instrumento de gestão. In: LIMONGIFRANÇA, A. C.; FLEURY, M. T. (orgs). As pessoas na organização. São Paulo: Gente, 2002. p. 73-86.

IENAGA, C. H. Competence-based management: seminário executivo. São Paulo: Dextron Consultoria Empresarial, 1998.

JORGE, F.C.; BITTENCOURT, J.P.; GALLELI, B. Avaliação de competências em uma instituição hospitalar: a visão de avaliados e avaliadores. Future Studies Research Journal, São Paulo, v. 6, n. 1, p. 3-31, jan./jun. 2014.

KAPLAN, R.; NORTON, D. Estratégia em ação: balanced scorecard. 9. ed., Rio de Janeiro: Elsevier, 1997.

KASS, G. V. An exploratory technique for investigating large quantities of categorical data. Journal of the Royal Statistical Society, v. 29, n. 2, p. 119-127, 1980. 
KING, A. W.; FOWLER, S. W.; ZEITHAML, C.P. Competências organizacionais e vantagem competitiva: o desafio da gerência intermediária. RAE - Revista de Administração de Empresas, v. 42, n. 1, p. 36-49, jan./mar. 2002.

KOUZES, J. M.; POSNER, B. Z. As cinco práticas da liderança exemplar. In: BIECH, E. (coord.). Manual de liderança da ASTD: a melhor fonte de informação sobre a arte de liderar. São Paulo: Elsevier, 2010.

LEME, R. Avaliação de desempenho com foco em competência: a base para remuneração por competências. Rio de Janeiro: Qualitymark, 2006.

MALHOTRA, N. Pesquisa de marketing: uma orientação aplicada. Porto Alegre: Bookman, 2006.

MARTINS, G. A.; THEÓPHILO, C. R. Metodologia de investigação científica para ciências sociais aplicadas. 2. ed. São Paulo: Atlas, 2009.

MINTZBERG, H.; AHLSTRAND, B.; LAMPEL, J. Safári de estratégia. Porto Alegre: Bookman, 2010.

MOHRMAN, S. A.; WORLEY, C. G. Dealing with rough times: a capabilities development approach to surviving and thriving. Human Resource Management, v. 48, n. 3, p. 433-445, maio/jun. 2009.

MOURA, D. L. et al. Competências requeridas no mercado globalizado. In: FISCHER, A. L.; DUTRA, J. S.; AMORIM, W. A. C. (org.). Gestão de pessoas: desafios estratégicos de organizações contemporâneas. São Paulo: Atlas, 2009. p. 77-98.

ODERICH, C. Gestão de competências gerenciais: noções e processos de desenvolvimento. In: RUAS, R.; ANTONELLO, C. S.; BOFF, L H. (org.). Os novos horizontes da gestão: aprendizagem organizacional e competências. Porto Alegre: Bookman, 2005. p. 88-115.

PEREIRA, M. C. B. RH Essencial: gestão estratégica de pessoas e competências. São Paulo: Saraiva, 2014.

PICCHIAI, D.; NERY, A. R. L. Estudo de caso de dois hospitais: estratégias, estrutura, competências organizacionais e o desempenho financeiro. JBES - Jornal Brasileiro de Economia da Saúde, v. 7, n. 1, p. 17-27, 2015.

PICCOLOTTO, C. L.; VASSARI, S. A.; DUTRA, J. S. Percepção de gestores quanto ao papel da área de recursos humanos na gestão de mudança organizacional. In: DUTRA, J. S. (org.). Gestão de pessoas: práticas modernas e transformação nas organizações. São Paulo: Atlas , 2010.

PONTES, B. R. Avaliação de desempenho: métodos clássicos e contemporâneos, avaliação por objetivos, competências e equipes. 11. ed. São Paulo: LTr, 2010.

QUINN, R. E. et al. Competências gerenciais: princípios e aplicações. 3. ed. Rio de Janeiro: Elsevier, 2003.

RESENDE, E. O livro das competências - desenvolvimento das competências: a melhor auto-ajuda para pessoas, organizações e sociedade. Rio de Janeiro: Qualitymark, 2000.

REZENDE, J. F. Balanced Scorecard e a gestão do capital intelectual: alcançando a performance balanceada na economia do conhecimento. Rio de Janeiro: Elsevier, 2003.

RICHARDSON, R. J. Pesquisa social: métodos e técnicas. São Paulo: Atlas, 2010. 
ROSINSKI, J. et al. Top-down and bottom-up approach to competence management implementation: a case of two central Banks. Tourism \& Management Studies, Faro, v. 10, edição especial, p. 26-34, 2014.

RUAS, R. Gestão por competências: uma contribuição à estratégia das organizações. In: RUAS, R.; ANTONELlO, C. S.; BOFF, L H. (org.). Os novos horizontes da gestão: aprendizagem organizacional e competências. Porto Alegre: Bookman, 2005, p. 34-54.

SOARES, J. F.; FARIAS, A. A.; CESAR, C. C. Introdução à Estatística. 2. ed. Rio de Janeiro: LTC, 2002.

ULRICH, D.; SMALLWOOD, N. A marca da liderança: priorizar o cliente, impulsionar o desempenho e criar valor duradouro. Rio de Janeiro: Best Seller, 2009.

WOOD, T. JR.; PICARELLI FILHO, V. Remuneração e carreira por habilidades e competências: preparando a organização para a era das empresas de conhecimento intensivo. São Paulo: Atlas, 2004.

ZARIFIAN, P. Objetivo competência: por uma nova lógica. São Paulo: Atlas, 2001. 